Delft University of Technology

\title{
Beam Experiments on Acceptance Criteria for Bridge Load Tests
}

Lantsoght, Eva; Yang, Yuguang; van der Veen, Cor; de Boer, A.; Hordijk, Dick

DOI

10.14359/51689786

Publication date

2017

Document Version

Accepted author manuscript

Published in

ACI Structural Journal

\section{Citation (APA)}

Lantsoght, E., Yang, Y., van der Veen, C., de Boer, A., \& Hordijk, D. (2017). Beam Experiments on Acceptance Criteria for Bridge Load Tests. ACI Structural Journal, 114(4), 1031-1042. [Title No. 114-S84]. https://doi.org/10.14359/51689786

\section{Important note}

To cite this publication, please use the final published version (if applicable).

Please check the document version above.

\section{Copyright}

Other than for strictly personal use, it is not permitted to download, forward or distribute the text or part of it, without the consent of the author(s) and/or copyright holder(s), unless the work is under an open content license such as Creative Commons.

\section{Takedown policy}

Please contact us and provide details if you believe this document breaches copyrights.

We will remove access to the work immediately and investigate your claim. 
This is an Accepted Manuscript of an article published by American concrete institute in ACI Structural Journal V. 114, No. 4, July-August 2017, available online: https://www.doi.org/10.14359/51689786.

\section{BEAM EXPERIMENTS ON ACCEPTANCE CRITERIA FOR BRIDGE}

\section{LOAD TESTS}

3 Eva O. L. Lantsoght ${ }^{1,2,3}$, Yuguang Yang $^{1}$, Cor van der Veen ${ }^{1}$, Ane de Boer ${ }^{4}$, and Dick A. Hordijk ${ }^{1}$

$4{ }^{1}$ Concrete Structures, Delft University of Technology, Delft, The Netherlands

$5 \quad 2$ Adstren, Quito, Ecuador.

$6 \quad{ }^{3}$ Universidad San Francisco de Quito, Quito, Ecuador.

$7 \quad{ }^{4}$ Rijkswaterstaat, Ministry of Infrastructure and the Environment, Utrecht, The Netherlands

9 Biography: ACI member Eva O. L. Lantsoght is a full professor at Universidad San Francisco de 10 Quito, a structural engineer at Adstren, Ecuador and a researcher at Delft University of Technology, 11 The Netherlands. She is a member of ACI Sub-Committee 445-0D Shear \& Torsion - Shear 12 Databases and of Joint ACI-ASCE Committee 421, Design of Reinforced Concrete Slabs, and an 13 associate member of ACI Committee 342, Evaluation of Concrete Bridges and Bridge Elements, 14 ACI Committee 437, Strength Evaluation of Existing Concrete Structures, and Joint ACI-ASCE 15 Committee 445, Shear and Torsion.

16 Yuguang Yang an assistant professor at Delft University of Technology, Delft, the Netherlands. He received his BS in civil engineering from Shanghai Jiao Tong University, Shanghai, China in 2005, and his $\mathrm{MS}$ and $\mathrm{PhD}$ in civil engineering from Delft University of Technology, Delft, the

19 Netherlands in 2007 and 2014, respectively. His research interests include shear strength of RC members, assessment of existing structures and measurement techniques.

21 Cor van der Veen is an associate professor at Delft University of Technology, Delft, The 22 Netherlands. He received his MSc and PhD from Delft University of Technology. He is a member 23 of various National Committees. His research interests include (very) high strength (steel fiber) 24 concrete, concrete bridges and computational mechanics.

25 Ane de Boer is a senior advisor at Rijkswaterstaat, the Ministry of Infrastructure and the 
1 Environment, Utrecht, The Netherlands. He received his MSc and PhD from Delft University of

2 Technology. He is a member of some National Committees, fib Special Activity Group 5 and

3 member of an IABSE Working Committee. His research interests are remaining lifetime, existing

4 structures, computational mechanics, traffic loads and composites.

5 Dick A. Hordijk is a full professor at Delft University of Technology, Delft, the Netherlands. He

6 received his $\mathrm{MS}$ and $\mathrm{PhD}$ in civil engineering from Delft University of Technology, Delft, the

7 Netherlands, in 1985 and 1990, respectively. His research interests include concrete fracture

8 mechanics, assessment of existing structures, structural application of new concrete types and 9 forensic engineering.

\section{ABSTRACT}

12 Loading protocols and acceptance criteria are available in the literature for load tests on buildings.

13 For bridges, proof load tests are interesting when crucial information about the structure is missing,

14 or when the uncertainties about the structural response are large. The acceptance criteria can then be

15 applied to evaluate if further loading is acceptable, or could lead to permanent damage to the

16 structure. To develop loading protocols and acceptance criteria for proof loading of reinforced

17 concrete bridges, beam experiments were analysed. In these experiments, different loading speeds,

18 constant load level times, numbers of loading cycles, and required number of load levels were

19 evaluated. The result of these experiments is the development of a standard loading protocol for the

20 proof loading of reinforced concrete bridges. Based on these limited test results, recommendations

21 for acceptance criteria are also proposed.

22 Keywords: acceptance criteria; beam test; bending; load test; loading protocol; proof loading; 23 reinforced concrete slab; shear; slab bridge. 
2 In the Netherlands, a large number of reinforced concrete bridges that were built in the decades

3 following the second World War are reaching the end of their originally devised service life

4 (Lantsoght et al., 2013). These bridges were designed for lower live loads than the currently

5 governing live loads (CEN, 2003) and were designed according to codes that allowed higher shear

6 capacities than according to the current provisions from Eurocode 2 (CEN, 2005). The result is that

7 the shear capacity of 600 reinforced concrete slab bridges is subject to discussion in the Netherlands.

8 To systematically rate these bridges, an assessment procedure following different Levels of

9 Approximation is developed (Lantsoght et al., (in press)), called Levels of Assessment (LoA), based

10 on slab shear experiments . Lower Levels of Assessment are less time-consuming, but give a more

11 conservative assessment. If a bridge rates too low at LoA I, the calculation can be refined with the

12 next LoA. Proof loading is used as the last resource, LoA IV. In a proof load test, a load is applied

13 that results in the same sectional shear as the live load model. If the bridge can carry the applied

14 proof load without showing signs of irreversible damage, it is experimentally demonstrated that the

15 bridge is suitable for carrying the loads prescribed in the code. This paper deals with the

16 development of a loading protocol and acceptance criteria for reinforced concrete bridges that need

17 to be verified in shear and in bending moment. The acceptance criteria are used during the test to

18 evaluate if further loading is allowed. This approach deviates from load testing of buildings, where

19 the measurement results are evaluated after the test to see if the structural behavior is acceptable. If

20 the acceptance criteria are exceeded, there is a chance that further increasing of the load will result

21 in irreversible damage in the bridge.

\section{RESEARCH SIGNIFICANCE}

23 The novelty of the presented work is that acceptance criteria and a loading protocol are developed 24 that are suitable for reinforced concrete bridges subjected to a proof load test. The development of 25 the acceptance criteria is based on carefully executed experiments on reinforced concrete beams 
1 without shear reinforcement. For the first time, a distinction between acceptance criteria for bending

2 moment and shear is made.

\section{LOAD TESTING AND ACCEPTANCE CRITERIA}

\section{$4 \quad$ Load testing}

5 Two types of load tests can be distinguished: diagnostic load tests and proof load tests. The goal of

6 diagnostic load tests (Fu et al., 1997; Olaszek et al., 2014; Russo et al., 2000; Sanayei et al., 2016)

7 is to improve analytical models of a structure based on measurements taken during a load test. A

8 diagnostic load test is carried out at relatively low load levels. A proof load test (Aguilar et al.,

9 2015; Casas and Gómez, 2013; Faber et al., 2000; Saraf et al., 1996) uses load levels that

10 correspond to the factored live loads, and is used to directly evaluate a structure.

11 A number of codes and guidelines exist for load testing of structures. ACI 437.2M-13 (ACI

12 Committee 437, 2013) and the German guidelines (Deutscher Ausschuss für Stahlbeton, 2000) deal

13 with load testing of existing buildings. The Irish (NRA, 2014), British (The Institution of Civil

14 Engineers - National Steering Committee for the Load Testing of Bridges, 1998) and French

15 (Cochet et al., 2004) guidelines describe diagnostic load tests on bridges. An NCHRP (NCHRP,

16 1998) report describes both diagnostic and proof load tests on bridges, but does not determine a

17 loading protocol, required load, and acceptance criteria for proof load tests.

18 In the Netherlands, a number of proof load tests have been carried out over the last decade in

19 order to establish guidelines for the proof load testing of reinforced concrete bridges. In particular,

20 bridges with ASR-damage were studied, such as the viaduct Heidijk (Dieteren and den Uijl, 2009),

21 the viaduct Vlijmen-Oost (Koekkoek et al., 2015b) and the viaduct Zijlweg (Koekkoek et al., 22 2015a). Additionally, a posted bridge, the viaduct De Beek (Koekkoek et al., 2016), a bridge that 23 rated insufficiently for bending moment, the Halvemaans Bridge (Fennis and Hordijk, 2014), and a 24 bridge with corrosion damage the viaduct Medemblik (Kapphahn, 2009), were proof load tested.

25 The Ruytenschildt Bridge (Lantsoght et al., 2016a) was tested to failure. 
2 ACI 437.2M-13 (ACI Committee 437, 2013) prescribes procedures and acceptance criteria for load

3 testing of concrete structures (prestressed and reinforced concrete, with a maximum concrete

4 compressive strength of $55 \mathrm{MPa}=8000 \mathrm{psi}$ ). The code describes a monotonic (Fig. 1a) and cyclic

5 loading protocol (Fig. 1b). In the monotonic loading protocol, each load step should be held for at

6 least 2 minutes, and the full test load should be applied for 24 hours. At least 24 hours after

7 removing the load, a final set of response measurements should be taken. For the cyclic loading

8 protocol, three load levels should be studied, with two cycles per load level (Casadei et al., 2005;

9 De Luca et al., 2014; Galati et al., 2008; Ziehl et al., 2008). The first two cycles study the

10 serviceability conditions, and the last two cycles study the full test load.

11 The first acceptance criterion is that the structure should show no evidence of failure. When

12 deflections exceed precalculated deflections, when cracking is observed, or when cracks indicating

13 anchorage problems appear, the licensed design professional should decide if the test can be

14 continued. At signs indicating that shear failure is imminent, the structure is considered as having

15 failed the load test. For monotonic loading, the measured deflection after the test (i.e. the residual

16 deflection) is limited to:

$$
\begin{gathered}
\Delta_{r} \leq \frac{\Delta_{l}}{4} \\
\Delta_{l} \leq \frac{l_{t}}{180}
\end{gathered}
$$

19 For a cyclic loading protocol, the first acceptance criterion is the deviation from linearity index, $I_{D L}$,

20 with the angles as shown in Fig. 2a:

$$
I_{D L}=1-\frac{\tan \left(\alpha_{i}\right)}{\tan \left(\alpha_{\text {ref }}\right)} \leq 0.25
$$

The second acceptance criterion, see Fig. $2 \mathrm{~b}$, the permanency ratio $I_{p r}$, is defined as: 


$$
I_{p r}=\frac{I_{p(i+1)}}{I_{p i}} \leq 0.5
$$

2 where $I_{p i}$ and $I_{p(i+1)}$ are the permanency indexes calculated for the $i$-th and (i+1)-th load cycles:

$$
\begin{gathered}
I_{p i}=\frac{\Delta_{r}^{i}}{\Delta_{\max }^{i}} \\
I_{p(i+1)}=\frac{\Delta_{r}^{(i+1)}}{\Delta_{\max }^{(i+1)}}
\end{gathered}
$$

5 The third acceptance criterion requires that the residual deflection, $\Delta_{r}$, measured at least 24 hours

6 after removal of the load, fulfils Eq. (1).

\section{$7 \quad$ Acceptance criteria from the German guidelines}

8 The German guideline for load testing (Deutscher Ausschuss für Stahlbeton, 2000), originally 9 developed for concrete buildings, is suitable for plain and reinforced concrete. Testing of shear10 critical structures or structures that could exhibit a brittle failure mode is not allowed. A cyclic

11 loading protocol of three load levels with at least one cycle per level is prescribed. Five acceptance

12 criteria are defined in the German guideline. The first criterion is a limiting concrete strain:

$$
\varepsilon_{c}<\varepsilon_{c, l i m}-\varepsilon_{c 0}
$$

14 The measured strain $\varepsilon_{c}$ should be smaller than the limiting strain $\varepsilon_{c, l i m}(0.6 \%$, or $0.8 \%$ if the 15 compressive strength is larger than $25 \mathrm{MPa}=3626 \mathrm{psi}$ ) minus the strain $\varepsilon_{c 0}$ due to the permanent loads. In practice, $\varepsilon_{c 0}$ is taken from the linear finite element model that is used to prepare for a proof load test, and thus uses the assumption of linear elastic material behavior. The second criterion is a

18 limiting strain in the steel:

$$
\varepsilon_{s 2}<0.7 \frac{f_{y m}}{E_{s}}-\varepsilon_{s 02}
$$

This criterion becomes the following when the stress-strain relation of the steel is fully known:

$$
\varepsilon_{s 2}<0.9 \frac{f_{0.01 m}}{E_{s}}-\varepsilon_{s 02}
$$


1 The third criterion is based on the crack width $w$ and the increase in crack width, $\Delta w$, as given in

2 Table 1. The fourth acceptance criterion is that no non-linear behavior can occur, typically

3 evaluated on the load-deflection graph, or if more than $10 \%$ permanent deformation is found after

4 removing the load. The fifth criterion limits the strains in the shear span of beams without shear

5 reinforcement to $60 \%$ of the strains from Eq. (7) for the strain in the concrete compressive strut and

6 to $50 \%$ of the strains from Eqs. (8) or (9) for the strain in the shear reinforcement. A test also needs

7 to be stopped when the measurements indicate critical changes in the structure, when the stability of

8 the structure is endangered, and when critical displacements occur at the supports.

\section{EXPERIMENTS}

\section{Test setup and instrumentation}

11 Two beams are tested specifically to study the acceptance criteria, and two additional experiments

12 from earlier testing at Delft University of Technology (Yang et al., 2016) were added to complete

13 the analysis. The beams are simply supported and subjected to a single concentrated load at a

14 distance $a$ from the support. A sketch of the test setup is shown in Fig. 3a for beam P804 and in Fig.

$153 \mathrm{~b}$ for beam P502. The width of the support and loading plates was $100 \mathrm{~mm}$ (4 in.).

The instrumentation on the beam consists of LVDTs, laser distance finders and acoustic

17 emission sensors, see Fig. 3c. An overview of the functions of all applied sensors is given in Table

182.

\section{Specimens and materials}

20 The cross section of beam P804 is $800 \mathrm{~mm} \times 300 \mathrm{~mm}(31.5 \mathrm{in} \times 11.8 \mathrm{in})$ and of beam P502 the

21 cross section is $500 \mathrm{~mm} \times 300 \mathrm{~mm}(19.7 \mathrm{in} \times 11.8 \mathrm{in})$. Glacial river aggregates with a maximum

22 diameter of $16 \mathrm{~mm}(0.63 \mathrm{in})$ are used. The density of the concrete is $2429.6 \mathrm{~kg} / \mathrm{m}^{3}\left(152 \mathrm{lb} / \mathrm{ft}^{3}\right)$,

23 which gives a load of $23.8 \mathrm{kN} / \mathrm{m}^{3}\left(0.152 \mathrm{kip} / \mathrm{ft}^{3}\right)$. The measured values of the concrete compressive 24 strength at 28 days is given in Table 3.

In P804, 6 plain reinforcement bars of soft steel with $\phi=20 \mathrm{~mm}(0.78$ in) are used. In P502, 
13 plain reinforcement bars with $\phi=20 \mathrm{~mm}(0.78 \mathrm{in})$ are used. This reinforcement is similar to the

2 reinforcement (plain bars, relatively low yield strength) that can be found in existing reinforced

3 concrete bridges. The measured yield strength of the steel is $f_{y m}=296.8 \mathrm{MPa}$ (43047 psi) and the

4 measured tensile strength of the steel is $f_{u m}=425.9 \mathrm{MPa}(61771 \mathrm{psi})$.

In Table 3, the predicted maximum load to cause a bending moment failure is given as

$6 P_{\text {moment }}$ and the predicted maximum load to cause a shear failure is given as $P_{\text {shear }}$. The

7 determination of the maximum loads takes the selfweight of the beam into account, and uses the full

8 static scheme of the test setup. For $P_{\text {shear }}$, the expression from NEN-EN 1992-1-1:2005 was used

9 (CEN, 2005), with $C_{R d, d} \gamma_{c}=0.15$ for average values (König and Fischer, 1995). The expected

10 maximum load (the minimum of $P_{\text {moment }}$ and $P_{\text {shear }}$ ) is then highlighted in grey in Table 3.

\section{Loading procedure}

12 The loading protocol for experiments P804A1 and P804A2 was determined to study acceptance 13 criteria and come up with recommendations for bridges. P804B and P502A2 are analyzed for 14 acceptance criteria, but were testing using a faster loading protocol.

First, the typical ratio of the applied proof load to the maximum load to cause failure has to be estimated, to know which load levels in the beam tests will correspond to the loads in the field.

17 The results of viaduct Zijlweg are analyzed for this purpose (Koekkoek et al., 2015a). The failure 18 load is estimated with the Extended Strip Model, which leads to good predictions for the capacity of 19 reinforced concrete slab bridges (Lantsoght et al., 2016c). This analysis showed that the load level 20 that corresponds to the proof load is $46 \%$ of the estimated failure load (Lantsoght et al., 2016b). As 21 the depth of the field tests and the beams tested in the laboratory is similar, no influence of the size 22 effect is expected. According to ACI 437.2M-13 (ACI Committee 437, 2013), at least 3 load levels should be used. Instead of using two load cycles per load step, as shown in Fig. 1, $1+3$ cycles are carried out: in the first cycle, small steps are used to go to the load level, and then three cycles are carried 
1 out without intermediate steps. In the first cycle, steps of $2 \mathrm{kN}(0.45 \mathrm{kip})$ are used, and then the

2 measurements are checked to verify if no indication of nonlinearity or onset of damage can be

3 observed. After every cycle of the three regular cycles, the measurements are also checked for

4 nonlinearity or indications of the onset of damage. A baseline load level higher than $0 \mathrm{kN}$ is used, to

5 make sure all measurements remain activated.

In P804A1, the influence of the loading speed is studied. At a low load level, four different

7 loading speeds were used. The standard loading speed was determined based on the loading speed

8 used for viaduct De Beek (Koekkoek et al., 2016). In the test, the loading speed was constant at 5.4

$9 \mathrm{kN} / \mathrm{s}(1.21 \mathrm{kip} / \mathrm{s})$ for the first test location and $7.3 \mathrm{kN} / \mathrm{s}(1.64 \mathrm{kip} / \mathrm{s})$ for the second test location. A

10 loading speed of $5 \mathrm{kN} / \mathrm{s}(1.12 \mathrm{kip} / \mathrm{s})$ is taken as a reference speed for the laboratory tests. Since the

11 loading is displacement-controlled, the applied loading speed used in the laboratory is $0.2 \mathrm{~mm} / \mathrm{s}$ $12(0.008 \mathrm{in} / \mathrm{s})$. Additionally, the loading speeds $0.004 \mathrm{~mm} / \mathrm{s}(0.00016 \mathrm{in} / \mathrm{s}), 0.04 \mathrm{~mm} / \mathrm{s}(0.0016 \mathrm{in} / \mathrm{s})$ 13 and $0.4 \mathrm{~mm} / \mathrm{s}(0.016 \mathrm{in} / \mathrm{s})$ are tested. The full loading protocol, as executed during the test, is shown 14 in Fig. 4a and contains 42 load cycles and 8 load levels.

In P804A2, the influence of keeping the load constant was studied. The $1+3$ cycles loading

16 protocol was used starting at the second load level, but in the first cycle, the maximum load was

17 kept constant for 15 minutes, see Fig. 4b. In total, 17 load cycles and 5 load levels are tested. In 18 P804B (Fig. 4c), no cyclic loading was used; and in P502A2 (Fig. 4d), a cyclic loading protocol 19 with less cycles was used. In P804B, 11 load levels were used; and in P502A2, 8 load steps at 5 20 load levels were used.

\section{RESULTS AND DISCUSSION}

Test results

23 In P804A1, the first cracks developed prior to the first load level of $75 \mathrm{kN}$ (17 kip). At higher load 24 levels, more flexural cracks developed until yielding of the reinforcement caused a flexural failure 25 at $207 \mathrm{kN}$ (47 kip), see Fig. 5a. In P804A2, lengthening of the existing cracks from P804A1 
1 occurred. A brittle shear failure occurred at $232 \mathrm{kN}$ (52 kip), see Fig. 5b. P804B was tested on the

2 side of beam P804 that had no existing flexural cracks. A shear failure occurred at $196 \mathrm{kN}$ (44 kip),

3 see Fig. 5c. P502A2 had existing flexural cracks, and failed in flexure at $150 \mathrm{kN}$ (34 kip), see Fig.

$45 \mathrm{~d}$. The load-displacement diagram of all tests is given in Fig. 6. The values of the failure loads $P_{u}$

5 and observed failure modes (flexure "F" or shear "S") are given in Table 3. It can be seen that the

6 failure modes were generally predicted correctly. The four experiments are used to analyze four

7 cases: shear and flexural failures, both for previously cracked and uncracked beams.

\section{$8 \quad$ Loading speed}

9 In P804A1, the loading speed is varied: loading speeds of $0.004 \mathrm{~mm} / \mathrm{s}(0.00016 \mathrm{in} / \mathrm{s}), 0.04 \mathrm{~mm} / \mathrm{s}$ $10(0.0016 \mathrm{in} / \mathrm{s}), 0.02 \mathrm{~mm} / \mathrm{s}(0.008 \mathrm{in} / \mathrm{s})$ and $0.4 \mathrm{~mm} / \mathrm{s}(0.016 \mathrm{in} / \mathrm{s})$ are used. First, the effect of the

11 loading speed on the increase in residual deformation is studied. If the time-dependent behavior of 12 concrete plays an important role, it is expected that for slow loading speeds, the increase in residual 13 deformation will be relatively larger. The increase in residual deformations is calculated as:

$$
\operatorname{res}_{i}=\Delta_{r, 0, i}-\Delta_{r, 0,(\mathrm{i}-1)}
$$

15 No relation between res $_{i}$ and the loading speed could be found. Additionally, the relation between $\Delta_{r}$ and the loading speed is shown in Fig. 7a. The first point in this figure has a higher value, because in the first load cycle, the cracking moment was exceeded in the beam, which influenced the stiffness. The results shown no statistically relevant relation between $\Delta_{r}$ and the loading speed. Next, the relation between the reduction in stiffness (comparing cycles $i$ and $i-1)$ and the loading speed is studied. For slower loading speeds, a larger reduction in the stiffness is expected.

21 The stiffness of the unloading branch is analyzed, as it is less influenced by crack formation. It can 22 be concluded, see Fig. 7b, that the effect of the loading speed on the stiffness reduction is irrelevant 23 for the speeds used in field testing. Additionally, the influence of the loading speed on the strain rate and the energy in the cycle was found to be insignificant (Lantsoght et al., 2016b). 


\section{$1 \quad$ Number of loading cycles}

2 The influence of the number of loading cycles in P804A1 was studied at the $75 \mathrm{kN}$ load level (16.9

$3 \mathrm{kip})$ by using 8 loading at a speed of $0.2 \mathrm{~mm} / \mathrm{s}(0.008 \mathrm{in} / \mathrm{s})$ and 3 cycles at the other tested speeds.

4 The results are studied as a function of the energy in the cycle and in the loading branch of the

5 cycle, see Fig. 7c. It can be seen that the results stabilize in the $4^{\text {th }}$ cycle, which supports the 6 proposal for a loading protocol of $1+3$ cycles for higher load levels, and three cycles for lower 7 load levels.

\section{Constant load}

9 In P804A1 and P804A2, the period of time used for constant loading and between load cycles was evaluated. In P804A1, cycles 30 (30 minutes constant load and rest), 34 and 38 (15 minutes load

11 and rest) have longer constant loading and rest periods. In P804A2, during the first load cycle of 12 each load level the load was applied for 15 minutes, followed by a rest period of 15 minutes, see Fig. 13 4. From the test results of P804A1, it seems that after a longer loading period, the stiffness is larger.

14 In other words, a longer loading period seems to create some recuperation in the beam. In P804A2, 15 the reduction of the stiffness during the experiment was very small, because the beam was fully 16 cracked by P804A1. No effect of the constant loading periods is observed on the energy in the 17 cycles, nor on the residual deformations. When looking at the results of the measured strains, a 18 decrease in strain between the beginning and end of a loading cycle can be observed. However, 19 because the experiment is executed in a displacement-controlled way, this observation is related to 20 the effect that the applied load is reduced when the applied deformation is kept constant.

\section{Analysis of acceptance criteria from the German guidelines}

22 First, the criteria from the German guidelines (Deutscher Ausschuss für Stahlbeton, 2000) are 23 evaluated. The acceptance criterion related to the steel strain, Eqs. (8) and (9), is not evaluated 24 because this criterion requires the removal of the concrete cover, which is not always allowed by 25 the bridge owner. The first evaluated acceptance criterion is related to the concrete strain, Eq. (7), 
1 and the results of this analysis are given in Table 4, indicating the load at which the criterion is

2 exceeded, $P_{\varepsilon \max }$. The loads range from $44 \%$ to $62 \%$ of the failure load. This acceptance criterion can

3 thus be used in practice.

The second evaluated acceptance criterion is related to the crack width, see Table 1, and the results of this analysis are given in Table 4. P804B was not tested in a cyclic way, and in P502A2

6 crack widths were not measured, so that only the results of P804A1 and P804A2 are analyzed.

7 P804A1 is a test on a beam with no existing cracks, so the requirements for new cracks from Table

81 can be evaluated. P804A2 has existing cracks, so the requirements for existing cracks from Table

91 are governing. During P804A1, the criterion is exceeded at LVDT12 in the second load cycle $-\mathrm{a}$

10 result that would be too conservative for practice: further loading did not yet lead to irreversible

11 damage or failure. However, it must be noted that the absolute values of the measured crack widths

12 are extremely small. Therefore, it is proposed to omit all crack widths smaller than $0.05 \mathrm{~mm}(0.002$

13 in) for the analysis - these results are reported in Table 4. In P804A2, the criterion for the maximum

14 increase in crack width is exceeded at LVDT15 in load step 9. It can thus be concluded that this

15 acceptance criterion can be applied, provided that crack widths smaller than $0.05 \mathrm{~mm}(0.002 \mathrm{in})$ are 16 neglected.

18 deflection $\Delta_{r}$ should not be more than $10 \%$ of the maximum deflection in a load cycle $\Delta_{\max }$ is 19 evaluated. Since a baseline load level is used in the experiments, the residual deflection does not correspond to a case with a load of $0 \mathrm{kN}$ (0 kip). Therefore, the stiffness of the unloading branch is 21 used to find the residual deflection that would correspond to a load of $0 \mathrm{kN}(0 \mathrm{kip}), \Delta_{r}{ }^{*}$, as sketched 22 in Fig. 2b. The results are given in Table 4. In P804A1, the requirement is exceeded in the first load 23 cycle. In P804A2, the requirement is exceeded in the first load cycle if $\Delta_{r}$ is used, and after failure if $24 \Delta_{r}{ }^{*}$ is used. In P502A2, unloading to $0 \mathrm{kN}(0 \mathrm{kip})$ was used, so that $\Delta_{r}=\Delta_{r}{ }^{*}$. The results in Table 4 25 indicate that the acceptance criterion based on the residual deflection is not generally applicable. 


\section{Analysis of acceptance criteria from ACI 437.2M-13}

2 The deviation from linearity index $I_{D L}$, see Fig. 2a, is a function of the loading scheme. In P804A1,

3 the deviation from linearity index $I_{D L}$ is exceeded in the $10^{\text {th }}$ load cycle, one of the cycles to $75 \mathrm{kN}$

4 (16.9 kip). In P804A2, $I_{D L}$ was not exceeded in any load cycle. The deviation from linearity index $I_{D L}$ can only be used with the cyclic loading protocol described in ACI 437.2M-13 (ACI Committee 437, 2013), see Fig. 1b, which cannot directly be used for bridges.

Similarly, it is found that the permanency ratio $I_{P R}$ as an acceptance criterion can only be used together with the cyclic loading protocol from Fig. 1b, in which fixed values for the minimum and maximum loads need to be used (for example, by applying the loads in a load-controlled manner). If a manually operated system with hydraulic jacks is used in the field, reaching the exact

11 same load over several load cycles becomes difficult. If the value of the residual deformation in the $12 i+1$-th cycle is smaller than in the $i$-th cycle, or if the maximum deformation in the $i+1$-th cycle is 13 smaller than in the $i$-th cycle, $I_{P R}$ becomes negative, which disturbs the results. Finally, the criterion for the residual deflections can be evaluated. In ACI 437.2M-13 (ACI and in P804A2 only in the loading cycle to failure. In P502A2, the criterion is never exceeded. Again, it is concluded that a criterion based on residual deflections is not recommended.

\section{RECOMMENDATIONS FOR BRIDGE APPLICATIONS}

\section{Proposed loading procedure}

21 A cyclic loading protocol is recommended for load testing of bridges. Contrarily to ACI 437.2M-13 (ACI Committee 437, 2013), four load levels, and four cycles per load level are recommended. Of these four load cycles, the first cycle will be used to gradually go to the maximum load in the cycle, then keep the load constant until stabilization of the measurements, and then unload to the baseline 
1 cycles without intermediate steps to the maximum load of that load level are carried out. The four

2 recommended load levels are:

3 1. A low load level, to check proper functioning of all sensors;

2. The serviceability limit state load level;

3. An intermediate load level; experiments is sufficient to support the presented recommendations. As such, further research to

11 define the loading protocol is not urgently needed.

\section{Proposed acceptance criteria}

13 When analyzing the experimental results, the difference between acceptance criteria for shear and flexure, and between previously cracked in bending and uncracked conditions becomes clear. An overview of the recommended acceptance criteria for these resulting four cases is given in Table 5 . The concrete strain criterion, Eq. (7) from the German guideline (Deutscher Ausschuss für

17 Stahlbeton, 2000) is recommended. The requirements for $w_{\max }$ and $w_{\text {res }}$ from Table 1 are simplified 18 and crack widths of smaller than $0.05 \mathrm{~mm}(0.002 \mathrm{in})$ are neglected.

The deviation from linearity index $I_{D L}$ depends on the loading protocol, see Fig. 2a. A simplification of this acceptance criterion uses the stiffness reduction, based on the stiffness as the

21 tangent in the load-displacement graph. An overview of these results is given in Table 4. For P804A1, the first loading step had a low stiffness as the result of the occurrence of the first crack, so 23 that the second loading cycle is used instead. In P804B, small steps were used to increase the load, 24 which makes it difficult to find the stiffness from the load-displacement diagram. For the case of a test for flexure, with no previous bending cracks, a stiffness reduction of $\leq 25 \%$ can be used as an 

21 tests.

acceptance criterion, whereas for the other cases, a stricter limit of 5\% can be recommended.

The deformation profiles in the longitudinal and transverse direction, as well as the loaddisplacement diagram should be evaluated in real time during the load test. The stiffness criterion is closely related to the load-displacement diagram. An example of the deformation profiles from P804A1 is given in Fig. 9. For the horizontal deformations, it can be seen that the shape of the profile changes at $120 \mathrm{kN}$ (27.0 kip). For the vertical deformations, a similar observation can be made at $160 \mathrm{kN}$ (36.0 kip). The results of the four experiments, considering the horizontal and vertical deformation profiles, are presented in Table 4. In P804A2, the vertical deformation plot did not signal distress prior to failure, but in all other cases both the horizontal and vertical deformation plot showed changes well in advance of failure. The analysis of these plots is thus recommended as an acceptance criterion.

These proposed acceptance criteria for bridge load tests are based on the presented preliminary study, which was limited to four experiments. Further experiments, especially on beams failing in shear, can be recommended to fine-tune and optimize the proposed acceptance criteria.

\section{SUMMARY AND CONCLUSIONS}

Proof load testing is considered the last method for rating of reinforced concrete bridges before strengthening or replacement is recommended. The current codes and guidelines mostly deal with either diagnostic load testing for bridges or proof load testing of buildings. Guidelines for proof load testing of bridges, indicating the required measurements and interpretation thereof, are necessary, especially because of the risks involved with the high load levels necessary in proof load

This paper focuses on the development of acceptance criteria and a loading protocol for proof load testing of concrete bridges. Heavily instrumented reinforced concrete beams were tested in flexure and shear to evaluate of the acceptance criteria from the German guidelines and ACI 437.2M-13. Several parameters that influence the loading protocol were studied in depth, and a 
1 recommended loading protocol for bridge proof load tests was developed. For the acceptance

2 criteria, all load cycles of each test need to be evaluated. Therefore, the proposed acceptance criteria

3 can be considered as a preliminary result, based on exploratory testing, which needs further

4 experimental verification in the future. The proposed acceptance criteria are based on the existing

5 acceptance criteria, but have been adjusted for practical considerations related to bridge proof load

6 testing.

\section{ACKNOWLEDGMENTS}

8 The authors wish to express their gratitude and sincere appreciation to the Dutch Ministry of

9 Infrastructure and the Environment (Rijkswaterstaat) for financing this research work. The work in

10 the laboratory of our colleague Albert Bosman is gratefully acknowledged. The authors also value

11 the contributions of our colleague Rutger Koekkoek, former MSc thesis student Werner Vos and

12 Sonja Fennis from Rijkswaterstaat to the research on load testing.

$14 a=$ distance between the center of the load and the center of the support

$15 a_{v} \quad=$ distance between the face of the load and the face of the support

$16 d=$ effective depth

$17 f_{0.01 \mathrm{~m}}=$ average yield strength based on a strain of $0.01 \%$ (elastic zone)

$18 f_{c, c y l, m}=$ average cylinder concrete compressive strength

$19 f_{y m}=$ measured yield strength of steel

$20 f_{u m}=$ measured tensile strength of steel

$21 \lim =$ criterion that is limiting

$22 l_{t} \quad=$ span length

$23 \operatorname{res}_{i}=$ the increase in the residual deformation between loading cycles $(i-1)$ and $i$

$24 \quad s_{\text {laser }}=$ deflection as measured by the laser distance finders at the position of the load

$25 \tan \left(\alpha_{i}\right)=$ the secant stiffness at any point $i$ on the increasing loading portion of the load-deflection 
envelope

$2 \tan \left(\alpha_{r e f}\right)=$ the slope of the reference secant line for the load-deflection envelope

$3 w=$ crack width for a new crack

$4 \quad w_{\text {lim }}=$ limiting crack width, calculated based on $w_{\max }$

$5 w_{\max }=$ crack width at maximum load of a given load cycle for a new crack, or increase in crack

6 width at the maximum load for an existing crack

$7 \quad w_{\text {res }}=$ residual crack width at unloading of a given load cycle

$8 C_{R d, c}=$ calibration factor from Eurocode shear expression, $=0.18$

$9 \quad E_{s} \quad=$ modulus of elasticity of reinforcement steel

$10 \mathrm{~F}=$ flexural failure

$11 \quad F \quad=$ measured load

$12 \mathrm{FM}=$ failure mode

$13 \quad I_{D L} \quad=$ deviation from linearity index

$14 \quad I_{P i} \quad=$ permanency index at the $i$-th load cycle

$15 I_{P(i+1)}=$ permanency index at the $(i+1)$-th load cycle

$16 \quad I_{P R}=$ permanency ratio

17 Level = percentage of maximum load at which an acceptance criterion is exceeded

18 LS = load step

$19 P \quad=$ load

$20 \quad P_{d e f}=$ load in experiment at which the deformation profiles change

$21 \quad P_{E I} \quad=$ load in experiment at which stiffness criterion is exceeded

$22 P_{\min }=$ baseline load level

$23 \quad P_{\max }=$ maximum load in a given load cycle

$24 P_{\text {moment }}=$ calculated load at which a bending moment failure takes place

$25 P_{\text {shear }}=$ calculated load at which a shear failure takes place 
$1 P_{u} \quad=$ load at failure of the specimen

$2 P_{w}=$ load in experiment at which crack width criterion is exceeded

$3 P_{\varepsilon \max }=$ load in experiment at which strain criterion is exceeded

$4 \quad P_{\Delta} \quad=$ load in experiment at which residual deflection criterion is exceeded

$5 \operatorname{Red}_{E I}=$ reduction in the stiffness with regard to the first load cycle

$6 \mathrm{~S}=$ shear failure

$7 \quad \gamma_{c}=$ material factor for concrete, $=1.5$

$8 \quad \varepsilon_{c} \quad=$ strain measured during proof loading

$9 \varepsilon_{c, l i m}=$ limit value of the concrete strain : $0.6 \%$, and for $\geq$ B25 this can be increased up to $10 \quad$ maximum $0.8 \%$

$11 \varepsilon_{c 0} \quad=$ analytically determined short-term strain in the concrete caused by the permanent loads 12 that are acting on the structure before the application of the proof load

$13 \quad \varepsilon_{s 2}=$ steel strain during experiment: directly measured or derived from other measurements

$14 \varepsilon_{s 02}=$ analytically determined strain (assuming cracked conditions) in the reinforcement steel 15 caused by the permanent loads that are acting on the structure before the application of the 16 proof load

$17 \rho_{l} \quad=$ ratio of longitudinal reinforcement

$18 \Delta=$ deflection

$19 \quad \Delta_{l} \quad=$ maximum deflection

$20 \Delta$ lim,DAfStB $=$ limit to residual deflection given in the German guideline

$21 \Delta_{\text {lim, }, A C I}=$ limit to residual deflection given in ACI 437.2M-13 (ACI Committee 437, 2013)

$22 \Delta_{\max }=$ maximum deflection of a load cycle

$23 \Delta^{1}{ }_{\max }=$ maximum deflection during load cycle 1

$24 \Delta^{2}{ }_{\max }=$ maximum deflection during load cycle 2

$25 \Delta_{\max }^{i}=$ maximum deflection during load cycle $i$ 
$1 \quad \Delta^{i+1}{ }_{\max }=$ maximum deflection during load cycle $i+1$

$2 \quad \Delta_{r} \quad=$ residual deflection

$3 \Delta_{r}^{*}=$ residual deflection recalculated at a load of $0 \mathrm{kN}(0 \mathrm{kip})$

$4 \Delta_{r, i}{ }^{*} \quad=$ residual deflection recalculated at a load of $0 \mathrm{kN}$ (0 kip) in the $i$ th loading cycle

$5 \quad \Delta^{1}{ }_{r} \quad=$ residual deflection after load cycle 1

$6 \quad \Delta^{2}{ }_{r} \quad=$ residual deflection after load cycle 2

$7 \quad \Delta_{r}^{i} \quad=$ residual deflection after load cycle $i$

$8 \quad \Delta^{i+1}{ }_{r}=$ residual deflection after load cycle $i+1$

$9 \Delta w \quad=$ increase in crack width for an existing crack

\section{REFERENCES}

11 ACI Committee 437, 2013, "Code Requirements for Load Testing of Existing Concrete Structures 12 (ACI 437.2M-13) and Commentary ", Farmington Hills, MA, 24 pp.

13 Aguilar, C. V., Jáuregui, D. V., Newtson, C. M., Weldon, B. D. and Cortez, T. M., 2015, "Load 14 Rating a Prestressed Concrete Double-Tee Beam Bridge without Plans by Proof Testing,"

15 Transportation Research Board Annual Compendium of Papers, Washington DC, pp. 19.

16 Casadei, P., Parretti, R., Nanni, A. and Heinze, T., 2005, "In Situ Load Testing of Parking Garage

17 Reinforced Concrete Slabs: Comparison between $24 \mathrm{~h}$ and Cyclic Load Testing," Practice

18 Periodical on Structural Design and Construction, V. 10, No. 1, pp. 40-48.

19 Casas, J. R. and Gómez, J. D., 2013, "Load Rating of Highway Bridges by Proof-loading," KSCE 20 Journal of Civil Engineering, V. 17, No. 3, pp. 556-567.

21 CEN, 2003, "Eurocode 1: Actions on structures - Part 2: Traffic loads on bridges, NEN-EN 199122 2:2003," Comité Européen de Normalisation, Brussels, Belgium, 168 pp.

23 CEN, 2005, "Eurocode 2: Design of Concrete Structures - Part 1-1 General Rules and Rules for 24 Buildings. NEN-EN 1992-1-1:2005," Comité Européen de Normalisation, Brussels, Belgium, 229 pp. 
1 Cochet, D., Corfdir, P., Delfosse, G., Jaffre, Y., Kretz, T., Lacoste, G., Lefaucheur, D., Khac, V. L.

2 and Prat, M., 2004, "Load tests on highway bridges and pedestrian bridges," Sétra - Service

3 d'Etudes techniques des routes et autoroutes, Bagneux-Cedex, France, 60 pp. (in French)

4 De Luca, A., Zadeh, H. J. and Nanni, A., 2014, "In Situ Load Testing of a One-Way Reinforced

5 Concrete Slab per the ACI 437 Standard," Journal of Performance of Constructed Facilities, pp. 1-

$6 \quad 10$.

7 Deutscher Ausschuss für Stahlbeton, 2000, "DAfStb-Guideline: Load tests on concrete structures,"

8 Deutscher Ausschuss fur Stahlbeton, 7 pp. (in German)

9 Dieteren, G. G. A. and den Uijl, J. A., 2009, "Evaluation Proof Loading Heidijk," V. 2008-

DWARS-MOIO, TNO Bouw en Ondergrond / TU Delft, 70 pp. (in Dutch)

11 Faber, M. H., Val, D. V. and Stewart, M. G., 2000, "Proof load testing for bridge assessment and 12 upgrading," Engineering Structures, V. 22, pp. 1677-1689.

13 Fennis, S. A. A. M. and Hordijk, D. A., 2014, "Proof loading Halvemaans Bridge Alkmaar," Stevin 14 Report 25.5-14-05, Delft University of Technology, Delft, The Netherlands, 72 pp. (in Dutch)

15 Fu, G., Pezze III, F. P. and Alampalli, S., 1997, "Diagnostic Load Testing for Bridge Load Rating,"

16 Transportation Research Record, V. 1594, pp. 125-133.

17 Galati, N., Nanni, A., Tumialan, J. G. and Ziehl, P. H., 2008, "In-situ evaluation of two concrete 18 slab systems. I: Load determination and loading procedure," Journal of Performance of Constructed 19 Facilities, V. 22, No. 4, Jul-Aug, pp. 207-216.

20 Kapphahn, G., 2009, "Experimental Safety Analysis of Superstructure of Bridge Nr. 12 (14H04) in 21 street N240 in Medemblik," ifem, Markkleeberg, Germany, 70 pp. (in German)

22 Koekkoek, R. T., Lantsoght, E. O. L. and Hordijk, D. A., 2015a, "Proof loading of the ASR23 affected viaduct Zijlweg over highway A59," Stevin Report nr. 25.5-15-08, Delft University of 24 Technology, Delft, The Netherlands, $180 \mathrm{pp}$.

25 Koekkoek, R. T., Yang, Y., Fennis, S. A. A. M. and Hordijk, D. A., 2015b, "Assessment of Viaduct 
Vlijmen Oost by Proof Loading," Stevin Report 25.5-15-10, 126 pp.

2 Koekkoek, R. T., Lantsoght, E. O. L., Yang, Y. and Hordijk, D. A., 2016, "Analysis report for the

3 assessment of Viaduct De Beek by Proof Loading," Stevin Report 25.5-16-01, Delft University of

4 Technology, Delft, The Netherlands, $125 \mathrm{pp}$.

5 König, G. and Fischer, J., 1995, "Model Uncertainties concerning Design Equations for the Shear

6 Capacity of Concrete Members without Shear Reinforcement," CEB Bulletin 224, Model

7 Uncertainties and Concrete Barrier for Environmental Protection, July, pp. 49-100.

8 Lantsoght, E.O.L, van der Veen, C. and de Boer, A., 2016a, "Shear and moment capacity of the

9 Ruytenschildt bridge," IABMAS 2016, pp. 8.

10 Lantsoght, E.O.L., Yang, Y., van der Veen, C. and Bosman, A., 2016b, "Analysis of beam 11 experiments for stop criteria," Stevin Report 25.5-16-06, 135 pp.

12 Lantsoght, E. O. L., van der Veen, C., de Boer, A. and Walraven, J. C., 2013, "Recommendations

13 for the Shear Assessment of Reinforced Concrete Slab Bridges from Experiments " Structural 14 Engineering International, V. 23, No. 4, pp. 418-426.

15 Lantsoght, E. O. L., van der Veen, C., de Boer, A. and Alexander, S., 2016c, "Bridging the gap 16 between one-way and two-way shear in slabs," ACI SP International Punching Symposium, pp. 20.

17 Lantsoght, E. O. L., De Boer, A. and Van der Veen, C., (in press), "Levels of Approximation for 18 the shear assessment of reinforced concrete slab bridges," Structural Concrete, pp. 53.

19 NCHRP, 1998, "Manual for Bridge Rating through Load Testing," V. NCHRP Project 12-28(13)A, 20 Washington, DC, $152 \mathrm{pp}$.

21 NRA, 2014, "Load Testing for Bridge Assessment," National Roads Authority, Dublin, Ireland, 11 22 pp.

23 Olaszek, P., Lagoda, M. and Ramon Casas, J., 2014, "Diagnostic load testing and assessment of 24 existing bridges: examples of application," Structure and Infrastructure Engineering, V. 10, No. 6, 25 Jun 3, pp. 834-842. 
1 Russo, F. M., Wipf, T. J. and Klaiber, F. W., 2000, "Diagnostic Load Tests of a Prestressed

2 Concrete Bridge Damaged by Overheight Vehicle Impact," Transportation Research Record, V. $3 \quad 1696$, pp. 103-110.

4 Sanayei, M., Reiff, A. J., Brenner, B. R. and Imbaro, G. R., 2016, "Load Rating of a Fully 5 Instrumented Bridge: Comparison of LRFR Approaches," Journal of Performance of Constructed $6 \quad$ Facilities, V. 2016, No. 30, pp. 2.

7 Saraf, V. K., Nowak, A. S. and Till, R., 1996, "Proof load testing of bridges," Probabilistic 8 Mechanics, 526-529 pp.

9 The Institution of Civil Engineers - National Steering Committee for the Load Testing of Bridges, 10 1998, "Guidelines for the Supplementary Load Testing of Bridges," London, UK, 44 pp.

11 Yang, Y., van der Veen, C., Hordijk, D. and De Boer, A., 2016, "The shear capacity of reinforced 12 concrete members with plain bars," Structural Faults and Repair 2016, Forde, M., ed. Edinburgh, 132016, pp. 9.

14 Ziehl, P. H., Galati, N., Nanni, A. and Tumialan, J. G., 2008, "In-situ evaluation of two concrete 15 slab systems. II: Evaluation criteria and outcomes," Journal of Performance of Constructed 16 Facilities, V. 22, No. 4, Jul-Aug, pp. 217-227. 
2 List of Tables

3 Table 1 - Requirements for crack width for newly developing cracks $w$ and increase in crack width

$4 \Delta w$ for existing cracks.

5 Table 2 - Overview of applied sensors

$6 \quad$ Table 3 - Properties of specimens

7 Table 4 - Evaluation of existing and proposed acceptance criteria. Conversion: $1 \mathrm{kN}=0.22 \mathrm{kip}$

8 Table 5 - Overview of proposed acceptance criteria for reinforced concrete bridges. Conversion: 1

$9 \mathrm{~mm}=0.04$ in.

11 Table 1 - Requirements for crack width for newly developing cracks $w$ and increase in crack width $\Delta w$ for existing cracks.

\begin{tabular}{|l|l|l|}
\hline & During proof loading & After proof loading \\
\hline Existing cracks & $\Delta w \leq 0.3 \mathrm{~mm}=0.01$ in & $\leq 0.2 \Delta w$ \\
\hline New cracks & $w \leq 0.5 \mathrm{~mm}=0.02$ in & $\leq 0.3 w$ \\
\hline
\end{tabular}

Table 2 - Overview of applied sensors

\begin{tabular}{|l|l|}
\hline nr & purpose \\
\hline LVDT1 & horizontal deformation \\
\hline LVDT2 & horizontal deformation \\
\hline LVDT3 & horizontal deformation \\
\hline LVDT4 & horizontal deformation \\
\hline LVDT5 & horizontal deformation \\
\hline LVDT6 & horizontal deformation \\
\hline LVDT7 & horizontal deformation \\
\hline LVDT8 & horizontal deformation \\
\hline LVDT9 & vertical deformation \\
\hline LVDT10 & vertical deformation \\
\hline LVDT11 & vertical deformation \\
\hline LVDT12 & crack width \\
\hline LVDT13 & crack width \\
\hline LVDT14 & strain over 1 m \\
\hline LVDT15 & crack width \\
\hline LVDT16 & crack width \\
\hline
\end{tabular}




\begin{tabular}{|l|l|}
\hline Laser01 & deflection at support \\
\hline Laser02 & deflection under load \\
\hline Laser03 & deflection at support \\
\hline Laser04 & deflection under load \\
\hline
\end{tabular}

Table 3 - Properties of specimens. Conversion: $1 \mathrm{MPa}=0.145 \mathrm{ksi} ; 1 \mathrm{kN}=0.22 \mathrm{kip} ; 1 \mathrm{~mm}=$

0.04 in.

\begin{tabular}{|l||c|c|c|c|c|c|c|c|c|c|}
\hline Test & $\begin{array}{c}a \\
(\mathrm{~mm})\end{array}$ & $\begin{array}{c}d \\
(\mathrm{~mm})\end{array}$ & $a / d$ & $a_{v} / d$ & $\rho_{l}$ & $\begin{array}{c}f_{c, c y l, m} \\
(\mathrm{MPa})\end{array}$ & $P_{\text {shear }}(\mathrm{kN})$ & $\begin{array}{c}P_{\text {moment }} \\
(\mathrm{kN})\end{array}$ & $\begin{array}{c}P_{u} \\
(\mathrm{kN})\end{array}$ & $\mathrm{FM}$ \\
\hline P804A1 & 3000 & 755 & 3.97 & 3.84 & 0.83 & 63.51 & 273 & 199 & 207 & $\mathrm{~F}$ \\
\hline P804A2 & 2500 & 755 & 3.31 & 3.18 & 0.83 & 63.51 & 219 & 248 & 232 & $\mathrm{~S}$ \\
\hline P804B & 2500 & 755 & 3.31 & 3.18 & 0.83 & 63.51 & 219 & 248 & 196 & $\mathrm{~S}$ \\
\hline P502A2 & 1000 & 465 & 2.15 & 1.94 & 0.68 & 71.47 & 150 & 154 & 150 & $\mathrm{~F}$ \\
\hline
\end{tabular}

kip, $1 \mathrm{~mm}=0.04$ in.

\begin{tabular}{|l||c|c|c|c|}
\hline \multicolumn{5}{|c|}{ Strain criterion from German guideline } \\
\hline Test & $\begin{array}{c}\varepsilon_{c 0} \\
(\mu \varepsilon)\end{array}$ & $\begin{array}{c}\varepsilon_{c, \text { lim }}-\varepsilon_{c 0} \\
(\mu \varepsilon)\end{array}$ & $\begin{array}{c}P_{\varepsilon m a x} \\
(\mathrm{kN})\end{array}$ & $\begin{array}{c}\text { Level } \\
(\%)\end{array}$ \\
\hline P804A1 & 36 & 764 & 91 & 44 \\
\hline P804A2 & 33 & 767 & 120 & 52 \\
\hline P804B & 33 & 767 & 111 & 57 \\
\hline P502A2 & 22 & 778 & 93 & 62 \\
\hline
\end{tabular}

Crack width criterion from German guideline

\begin{tabular}{|c|c|c|c|c|c|c|c|c|}
\hline Test & $\mathrm{LS}$ & $\begin{array}{l}w_{\max } \\
(\mathrm{mm})\end{array}$ & $\begin{array}{l}w_{\text {res }} \\
(\mathrm{mm})\end{array}$ & $\begin{array}{l}w_{\text {lim }} \\
(\mathrm{mm})\end{array}$ & $\lim$ & LVDT & $\begin{array}{l}P_{w} \\
(\mathrm{kN})\end{array}$ & $\begin{array}{l}\text { Level } \\
(\%)\end{array}$ \\
\hline P804A1 & 30 & $\begin{array}{l}0.2441 \\
0.0021\end{array}$ & $\begin{array}{l}0.0760 \\
0.0640\end{array}$ & $\begin{array}{l}0.0732 \\
0.0006\end{array}$ & $w_{\text {lim }}$ & $\begin{array}{l}\text { LVDT15 } \\
\text { LVDT16 }\end{array}$ & 140 & 68 \\
\hline P804A1 & 38 & 0.5569 & 0.2156 & 0.1671 & $w_{\max }$ & LVDT15 & 180 & 87 \\
\hline P804A1 & 2 & 0.0024 & 0.0284 & 0.0007 & $w_{\text {lim }}$ & LVDT12 & 75 & 36 \\
\hline P804A2 & 9 & 0.3141 & 0.0144 & 0.0628 & $w_{\max }$ & LVDT15 & 160 & 69 \\
\hline \multicolumn{9}{|c|}{ Residual deformation criterion from German guideline and ACI 437.2M-13 } \\
\hline Test & $\mathrm{LS}$ & $\begin{array}{l}\Delta_{\max } \\
(\mathrm{mm})\end{array}$ & $\begin{array}{l}\Delta_{r} \\
(\mathrm{~mm})\end{array}$ & $\begin{array}{l}\Delta_{r}^{*} \\
(\mathrm{~mm})\end{array}$ & $\begin{array}{l}\Delta_{\text {lim,DAfStB }} \\
(\mathrm{mm})\end{array}$ & $\begin{array}{l}\Delta_{\lim , A C I} \\
(\mathrm{~mm})\end{array}$ & $\begin{array}{l}P_{\Delta} \\
(\mathrm{kN})\end{array}$ & $\begin{array}{l}\text { Level } \\
(\%)\end{array}$ \\
\hline P804A1 & 1 & 2.509 & 1.001 & 0.727 & 0.251 & 0.627 & 75 & 36 \\
\hline P804A2 & 1 & 3.172 & 0.416 & -0.082 & 0.317 & 0.793 & 75 & 32 \\
\hline P804A2 & 17 & 12.973 & 11.348 & 11.239 & 1.297 & 3.243 & 230 & 100 \\
\hline P502A2 & 7 & 5.262 & 0.311 & 0.311 & 0.526 & 1.315 & 150 & 100 \\
\hline \multicolumn{5}{|c|}{ Proposed stiffness criterion } & & & & \\
\hline Test & $\mathrm{LS}$ & $\begin{array}{l}\operatorname{Red}_{E I} \\
(\%)\end{array}$ & $\begin{array}{l}P_{E I} \\
(\mathrm{kN})\end{array}$ & $\begin{array}{l}\text { Level } \\
(\%)\end{array}$ & & & & \\
\hline
\end{tabular}




\begin{tabular}{|c|c|c|c|c|}
\hline P804A1 & 25 & 24.67 & 95 & 46 \\
\hline P804A1 & 26 & 51.79 & 120 & 58 \\
\hline P804A2 & 5 & 6.37 & 115 & 50 \\
\hline P804A2 & 17 & 15.14 & 230 & 100 \\
\hline P804B & 4 & 25.77 & 110 & 56 \\
\hline P502A2 & 2 & 21.72 & 75 & 50 \\
\hline \multicolumn{5}{|c|}{ Proposed criterion from deformation profiles } \\
\hline & \multicolumn{2}{|c|}{ Horizontal deformations } & \multicolumn{2}{|c|}{ Vertical deformations } \\
\hline Test & $\begin{array}{c}P_{\text {def }} \\
(\mathrm{kN})\end{array}$ & $\begin{array}{c}\text { Level } \\
(\%)\end{array}$ & $\begin{array}{c}P_{d e f} \\
(\mathrm{kN})\end{array}$ & $\begin{array}{c}\text { Level } \\
(\%)\end{array}$ \\
\hline P804A1 & 120 & 58 & 160 & 77 \\
\hline P804A2 & 200 & 87 & - & - \\
\hline P804B & 110 & 56 & 110 & 56 \\
\hline P502A2 & 125 & 83 & 125 & 83 \\
\hline
\end{tabular}

Table 5 - Overview of proposed acceptance criteria for reinforced concrete bridges.

Conversion: $1 \mathrm{~mm}=0.04 \mathrm{in}$.

\begin{tabular}{|l|l|l|}
\hline \multicolumn{1}{|c|}{} & \multicolumn{2}{|c|}{ Previously cracked in bending moment or not? } \\
\hline Failure mechanism & \multicolumn{1}{|c|}{ Uncracked } & \multicolumn{1}{c|}{ Cracked } \\
\hline Flexural failure & Concrete strains (Eq. (7)) & Concrete strains (Eq. (7)) \\
& $w_{\max } \leq 0.5 \mathrm{~mm}$ & $w_{\max } \leq 0.5 \mathrm{~mm}$ \\
& $w_{\text {res }} \leq 0.1 \mathrm{~mm}$ & $w_{\text {res }} \leq 0.1 \mathrm{~mm}$ \\
& Stiffness reduction $\leq 25 \%$ & Stiffness reduction $\leq 5 \%$ \\
& Deformation profiles & Deformation profiles \\
& Load-displacement graph & Load-displacement graph \\
\hline Shear failure & Concrete strains (Eq. (7)) & Concrete strains (Eq. (7)) \\
& $w_{\text {max }} \leq 0.3$ mm & Stiffness reduction $\leq 5 \%$ \\
& Stiffness reduction $\leq 5 \%$ & Deformation profiles \\
& Deformation profiles & Load-displacement graph \\
& Load-displacement graph & \\
\hline
\end{tabular}




\section{$1 \quad$ List of Figures}

2 Fig. 1-Loading protocols from ACI 437.2M-13 (ACI Committee 437, 2013): (a) monotonic

3 loading protocol; (b) cyclic loading protocol

4 Fig. 2- Definitions used for the acceptance criteria from ACI 437.2M-13 (ACI Committee 437, 5 2013): (a) Deviation from Linearity, $I D L$

6 Fig. 3- (a) Test setup and geometry of P804A1, P804A2 and P804B; (b) Test setup and geometry

7 for P502A2; (c) instrumentation on P804A1. Conversion: $1 \mathrm{~mm}=0.04$ in.

8 Fig. 4-Loading scheme of: (a) P804A1, (b) P804A2, (c) P804B, (d) P502A2.

9 Fig. 5 - Observed failure modes: (a) P804A1; (b) P804A2; (c) P804B; (d) P502A2.

10 Fig. 6 - Measured load-displacement diagrams: (a) P804A1; (b) P804A2; (c) P804B; (d) P502A2.

11 Conversion: $1 \mathrm{~mm}=0.04 \mathrm{in}$.

12 Fig. 7 - Evaluation of P804A1 for loading protocol: (a) Relation between residual deflection $\Delta_{r}$ and

13 the loading speed; (b) Relation between stiffness reduction and loading speed; (c) Influence of 14 number of cycles on energy in cycle or energy in loading branch of cycle. Conversion: $1 \mathrm{~mm}=0.04$ 15 in, $1 \mathrm{kNm}=0.7 \mathrm{kip}-\mathrm{ft}$.

16 Fig. 8 - Example of the proposed loading protocol. Conversion: $1 \mathrm{kN}=0.22 \mathrm{kip}$.

17 Fig. 9 - Deformation plots: (a) upper layer of horizontal deformations; (b) lower layer of horizontal 18 deformations; (c) vertical deformations. Conversion: $1 \mathrm{~mm}=0.04 \mathrm{in}$. 

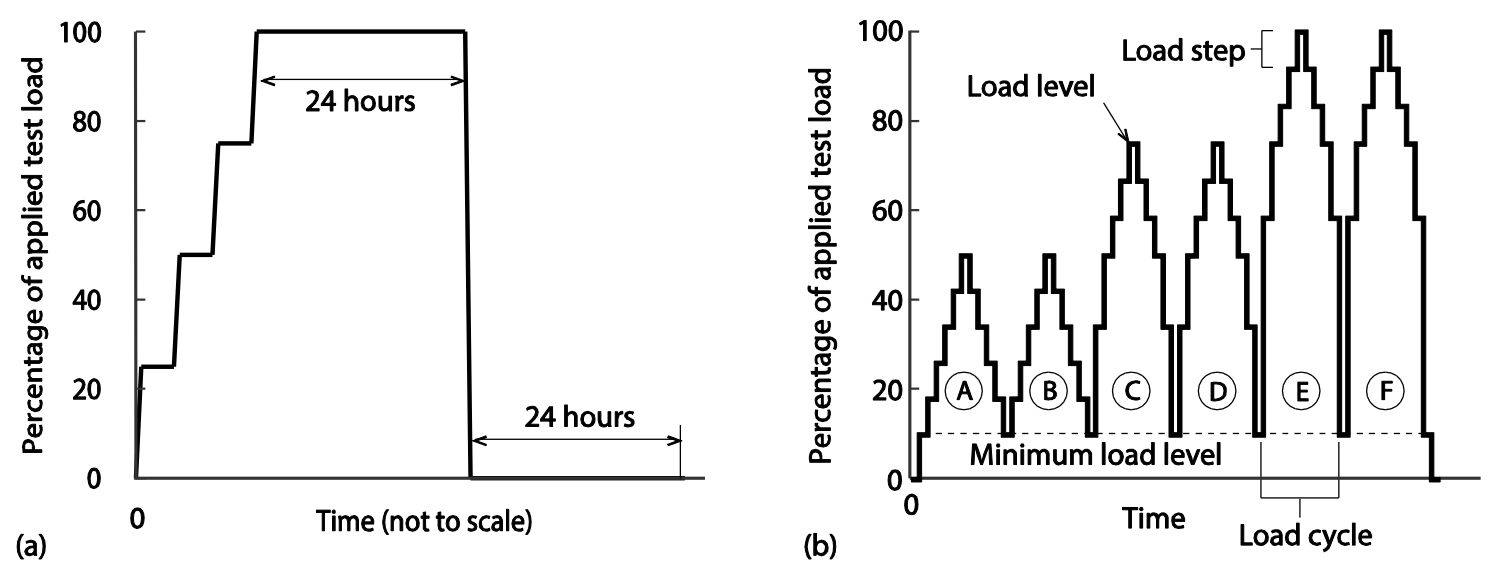

2 Fig. 1-Loading protocols from ACI 437.2M-13 (ACI Committee 437, 2013): (a) monotonic loading protocol; (b) cyclic loading protocol

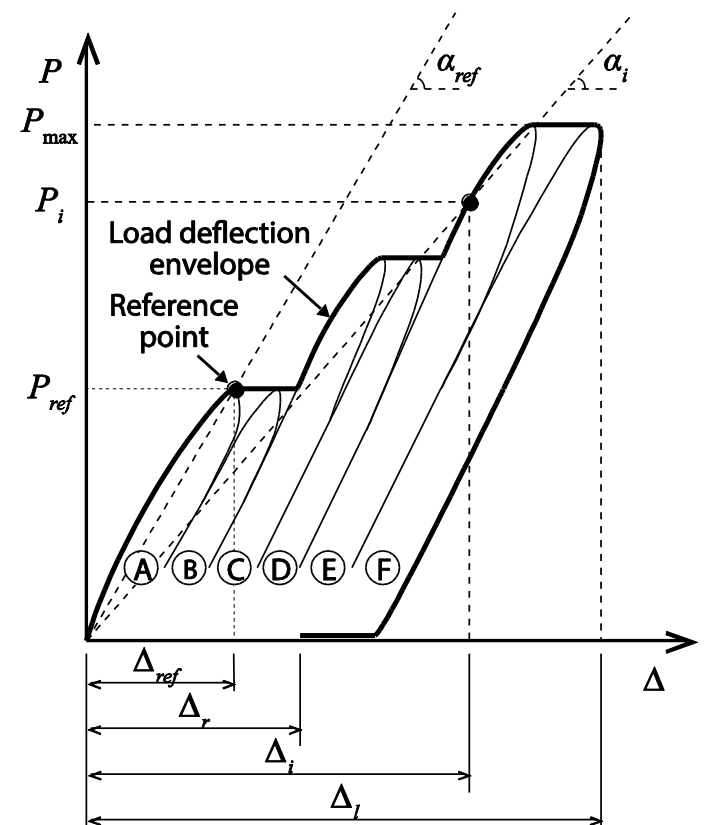

(a)

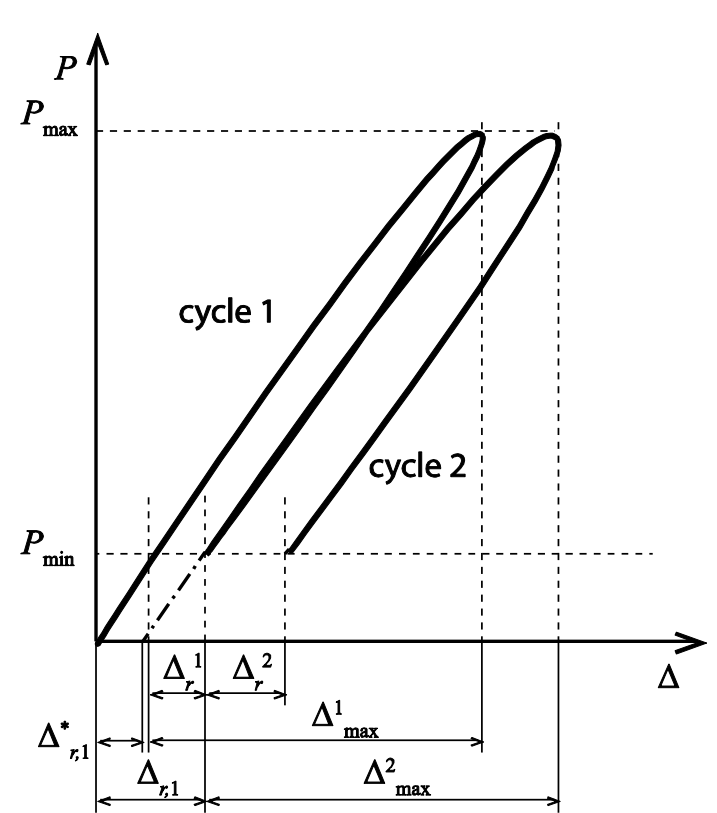

(b)

Fig. 2- Definitions used for the acceptance criteria from ACI 437.2M-13 (ACI Committee deflection after a cycle $\Delta_{r, 1}$ and the calculated value using the stiffness of the unloading branch to zero load, $\Delta_{r, 1}^{*}$. 

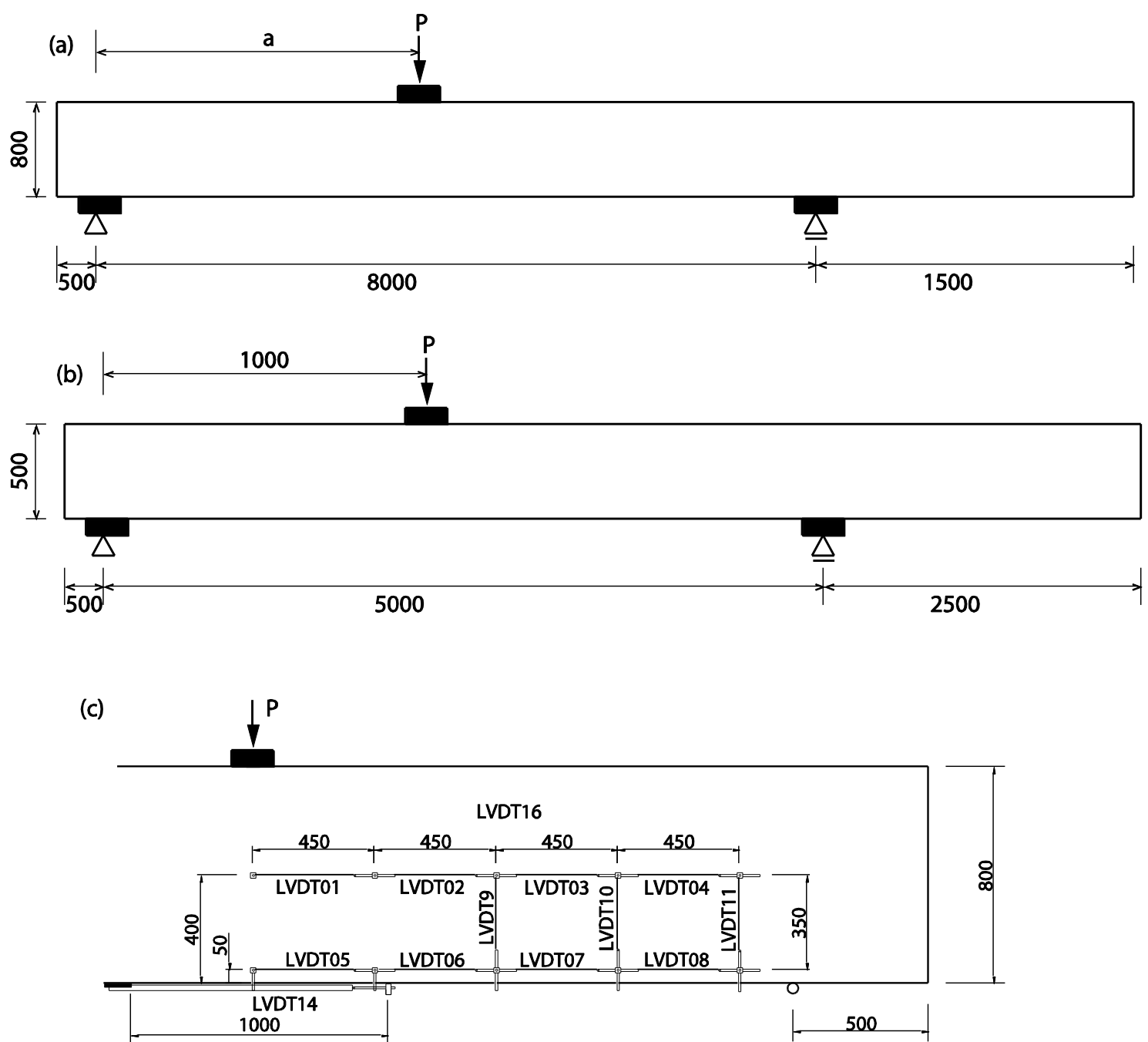

Fig. 3- (a) Test setup and geometry of P804A1, P804A2 and P804B; (b) Test setup and geometry for P502A2; (c) instrumentation on P804A1. Conversion: $1 \mathrm{~mm}=0.04$ in. 

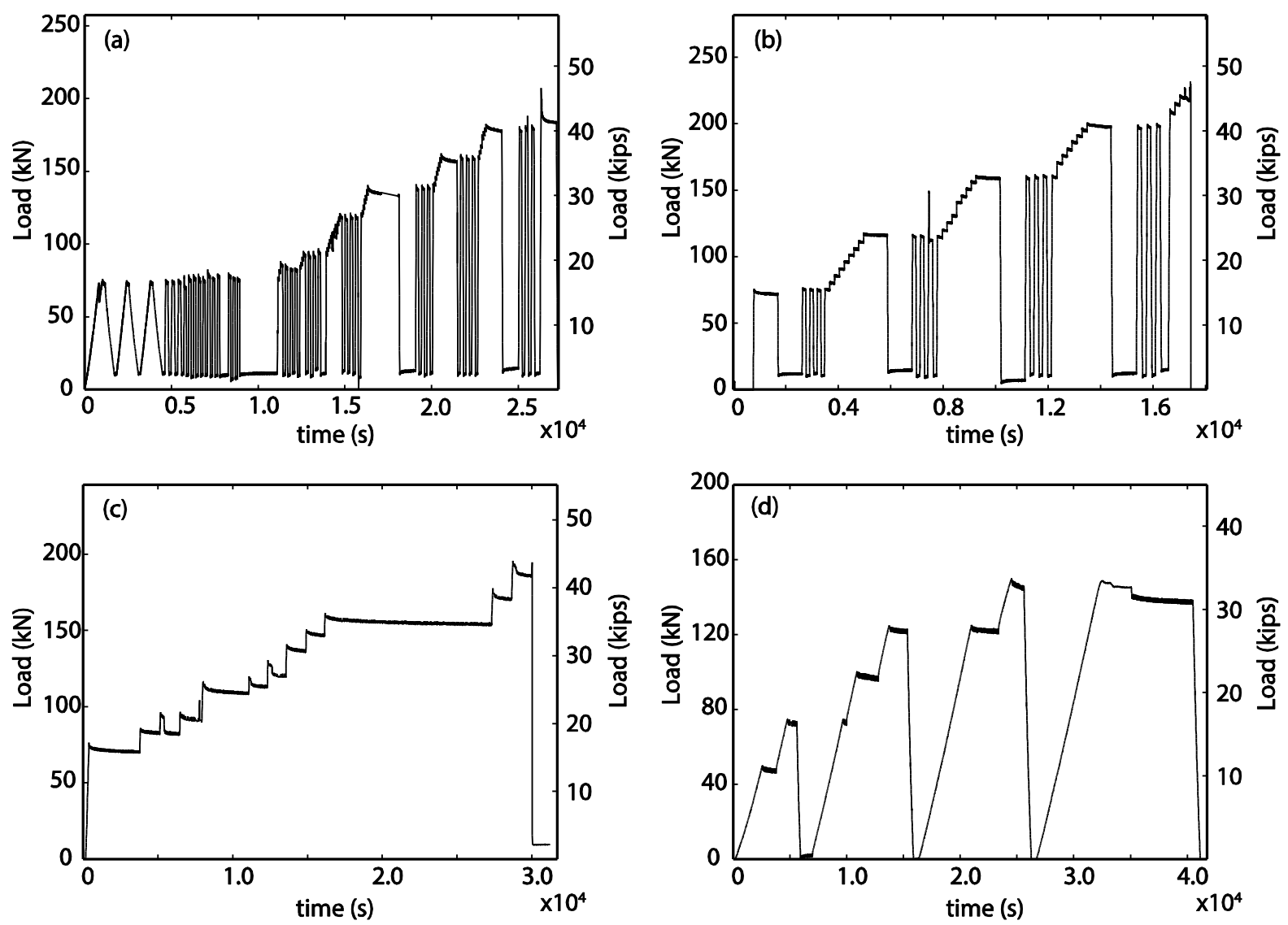

Fig. 4-Loading scheme of: (a) P804A1, (b) P804A2, (c) P804B, (d) P502A2.

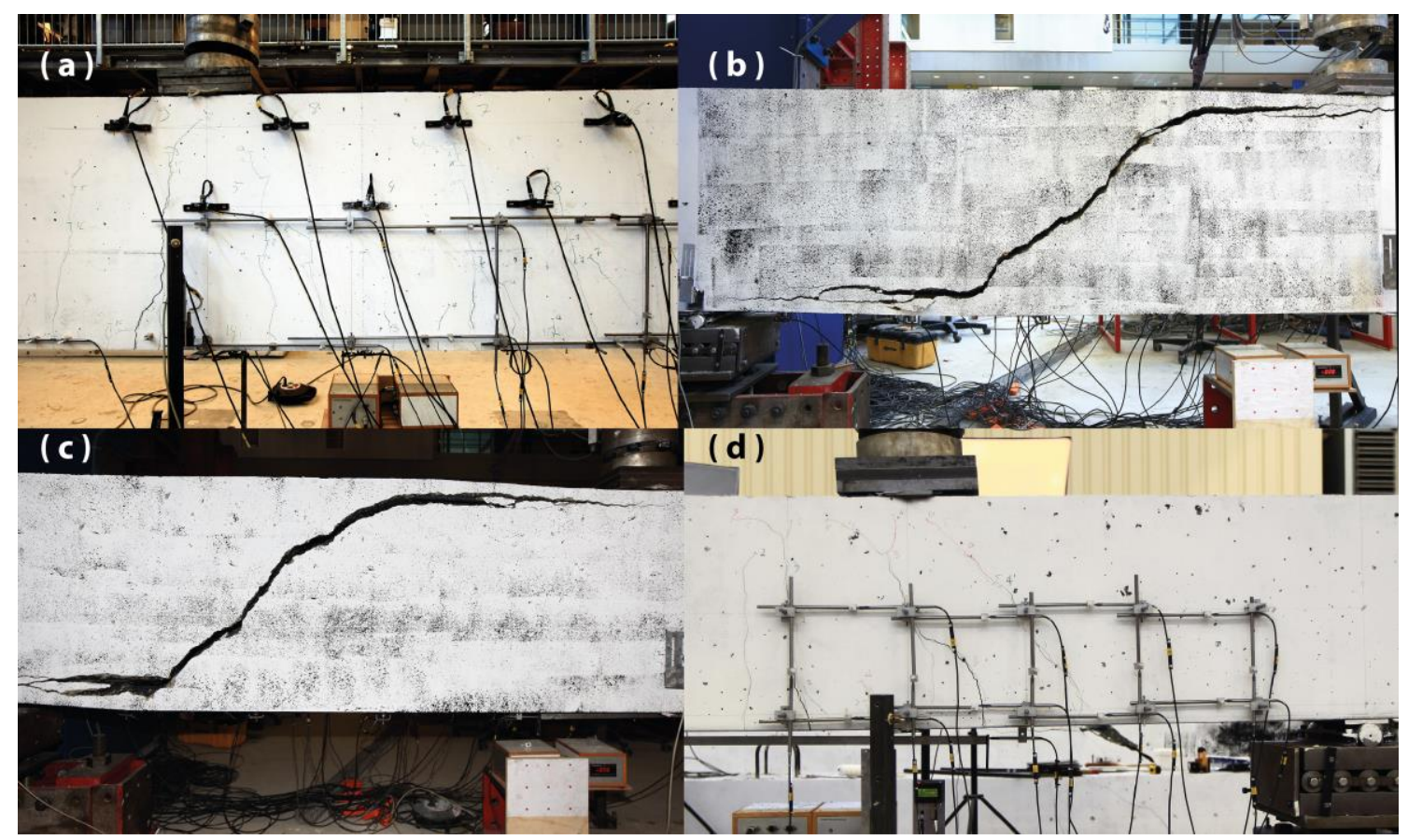

Fig. 5 - Observed failure modes: (a) P804A1; (b) P804A2; (c) P804B; (d) P502A2. 

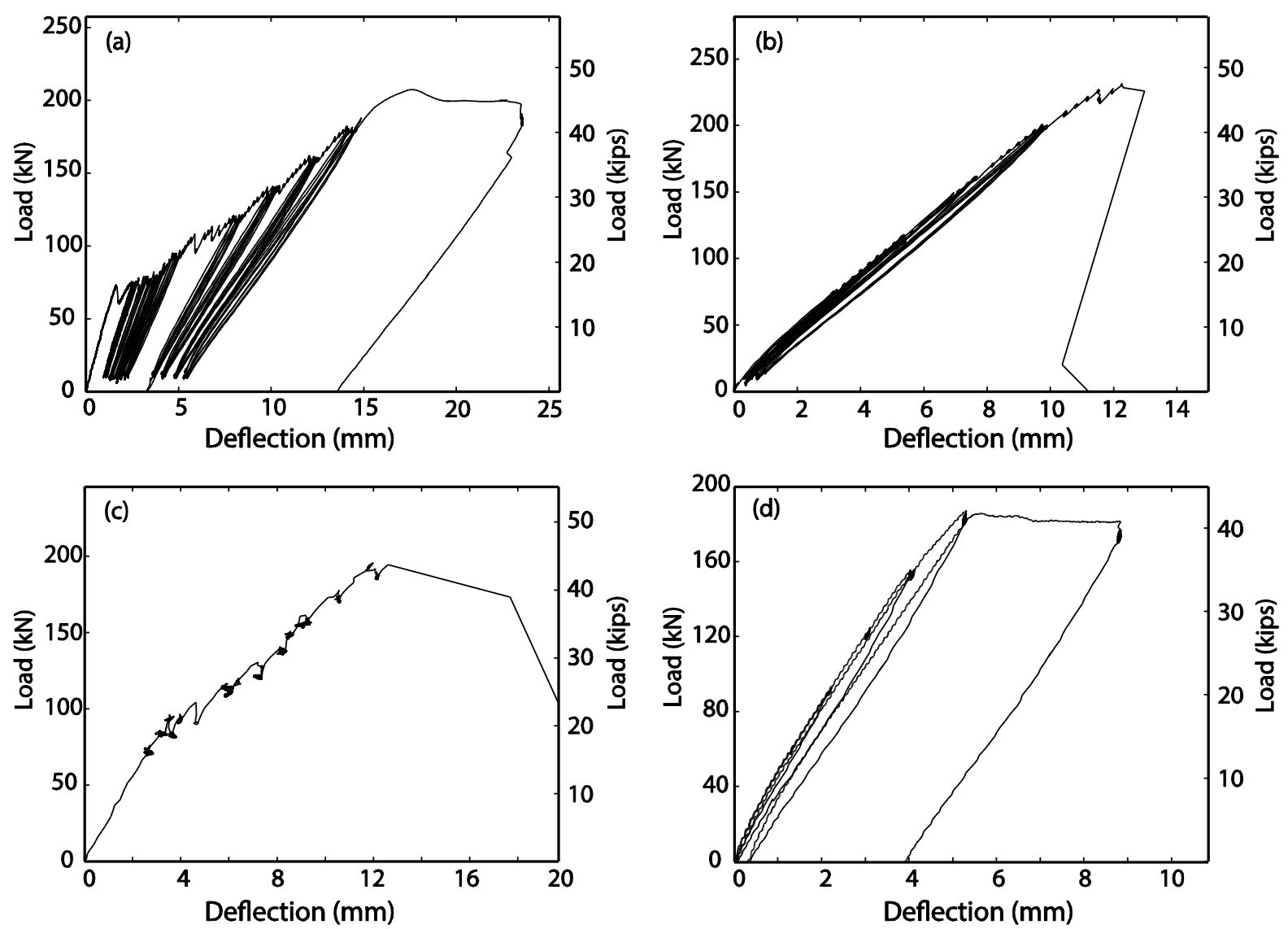

Fig. 6 - Measured load-displacement diagrams: (a) P804A1; (b) P804A2; (c) P804B; (d)

P502A2. Conversion: $1 \mathrm{~mm}=0.04$ in. 

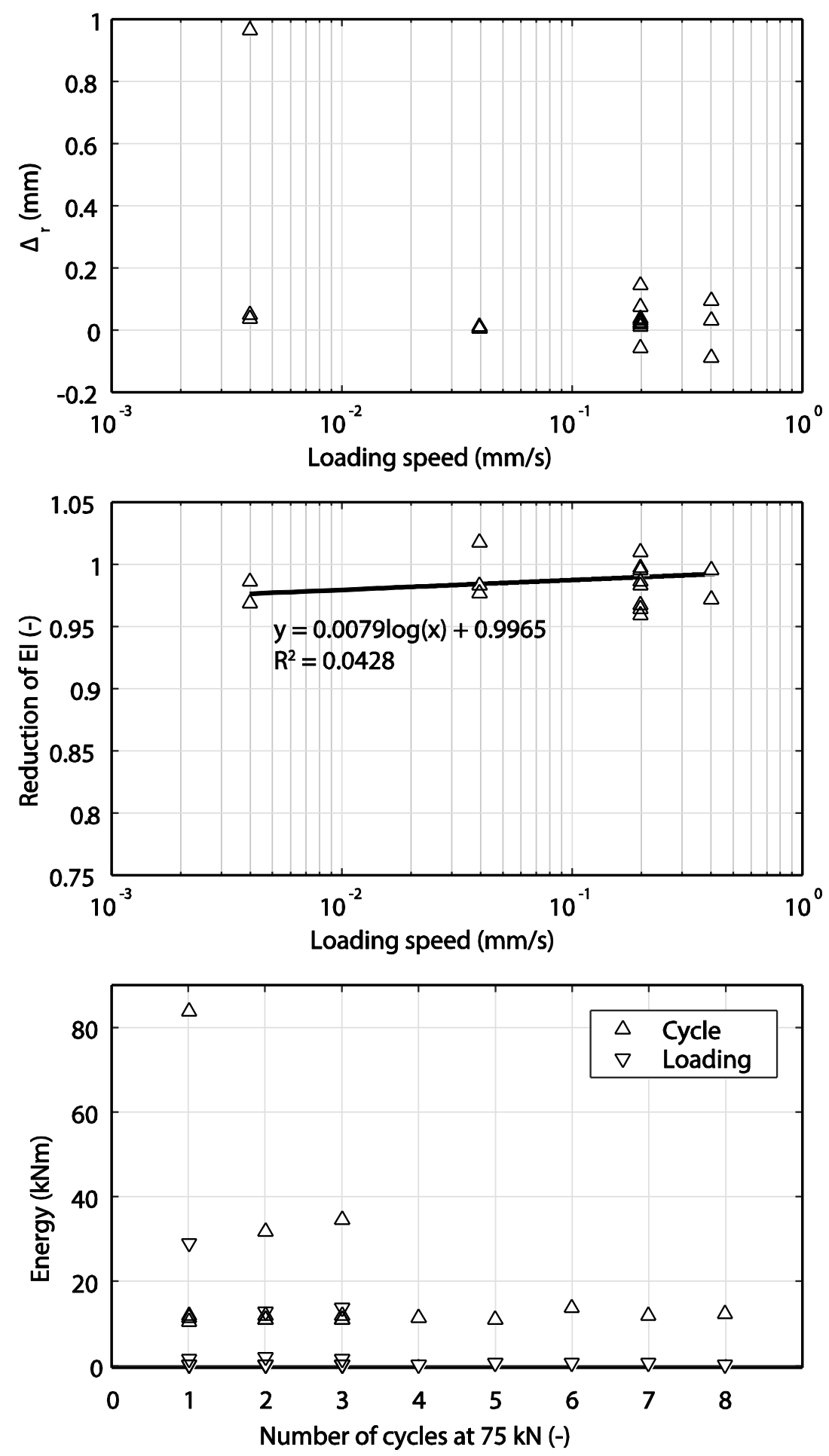

2 Fig. 7 - Evaluation of P804A1 for loading protocol: (a) Relation between residual deflection $3 \quad \Delta_{r}$ and the loading speed; (b) Relation between stiffness reduction and loading speed; (c) $4 \quad$ Influence of number of cycles on energy in cycle or energy in loading branch of cycle.

Conversion: $1 \mathrm{~mm}=0.04 \mathrm{in}, 1 \mathrm{kNm}=0.7 \mathrm{kip}-\mathrm{ft}$. 


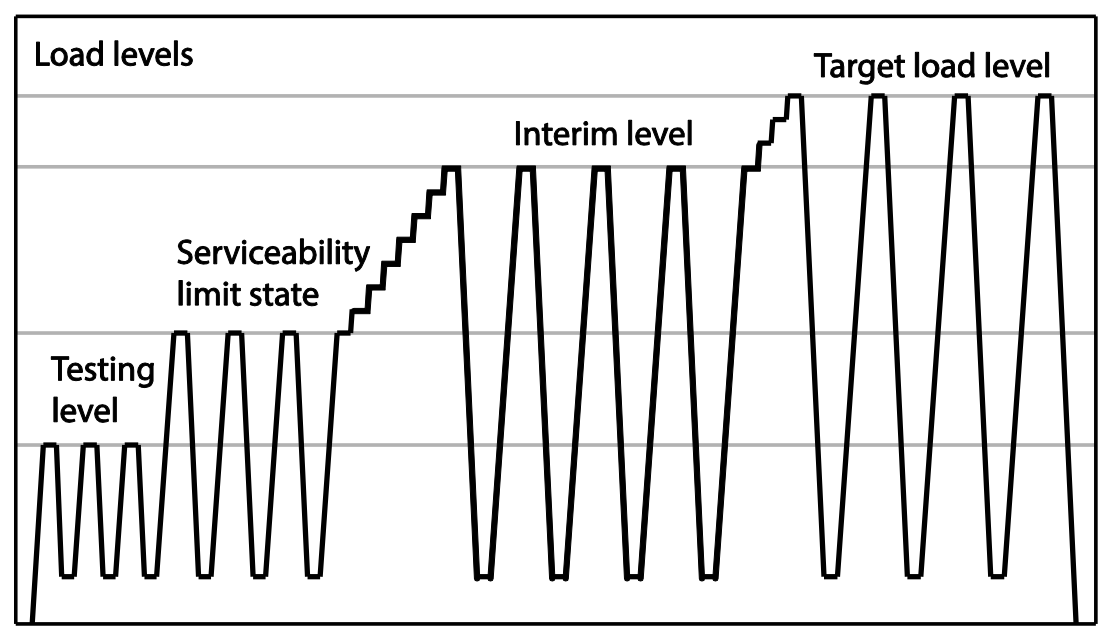

Fig. 8 - Example of the proposed loading protocol. Conversion: $1 \mathrm{kN}=0.22 \mathrm{kip}$. 

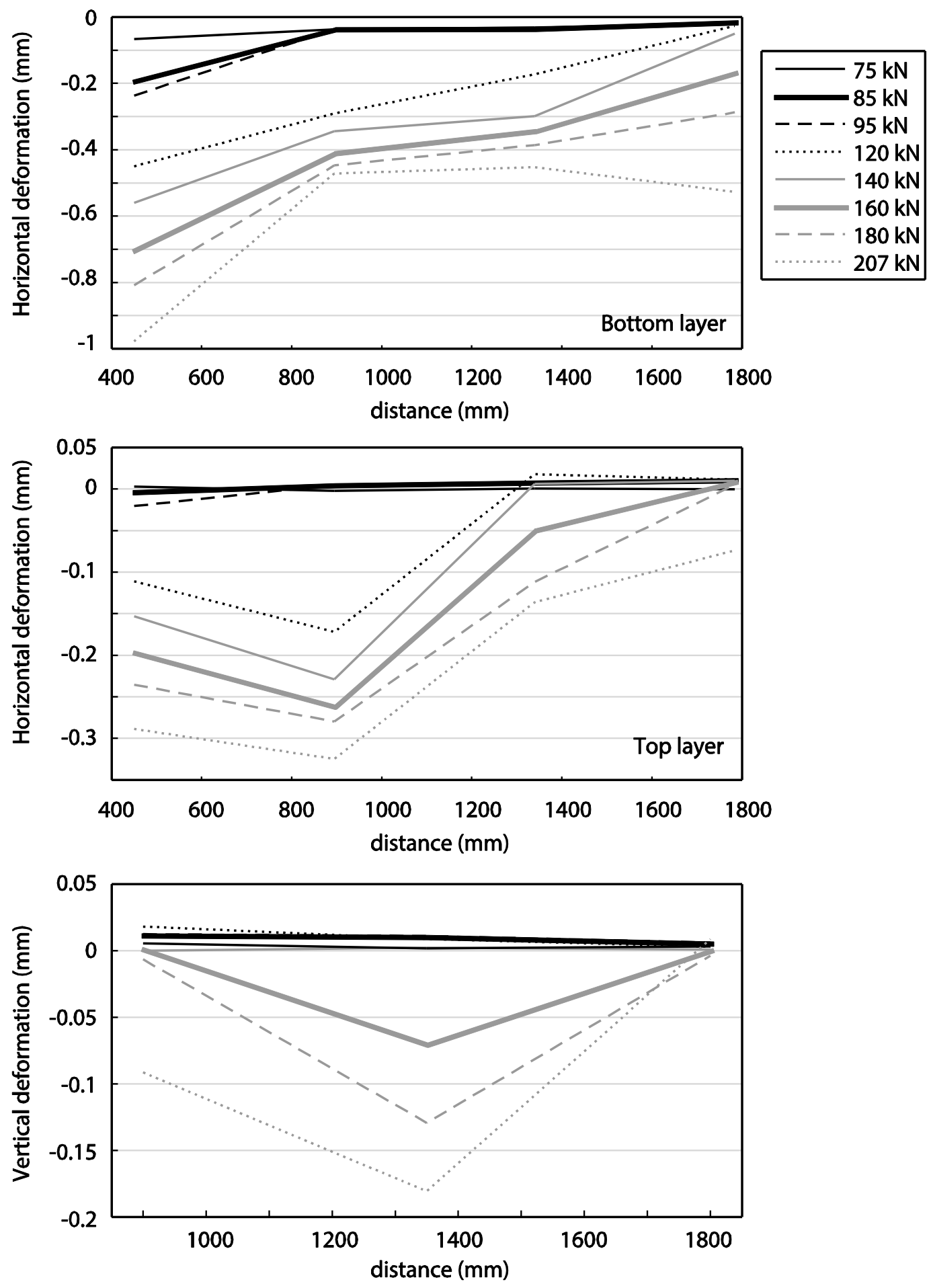

2 Fig. 9-Deformation plots: (a) upper layer of horizontal deformations; (b) lower layer of

horizontal deformations; (c) vertical deformations. Conversion: $1 \mathrm{~mm}=0.04$ in. 